\title{
Effects of remoteness on the quality of education: A case study from North Indian schools
}

\author{
Sugata Mitra \\ Newcastle University, UK \\ Ritu Dangwal and Leher Thadani \\ The NIIT Institute of Information Technology, India
}

\begin{abstract}
This paper studies the relationship between geographic remoteness and the quality of primary education in rural Northern India. It then discusses this relationship in the context of educational technology. There is a significant negative correlation between the quality of education and the distance of a school from the nearest urban centre. No correlation was seen between the quality of education and average number of students per teacher or per classroom. The authors suggest that teacher migration and desire for migration are directly responsible for poorer quality of education in remote areas. The role of technology, therefore, becomes vital in such areas. We propose that appropriate educational technology, if designed for that purpose, will be needed to improve the quality of education in non-urban regions where good teachers will not remain.
\end{abstract}

\section{Background}

\section{Geographic location and the quality of education}

A recent and exhaustive "Status of Education" report (ASER, 2006) showed that approximately $20 \%$ of the children enrolled in standards 6-8 in government schools all over India cannot read a short story, and $17 \%$ of the children in the same age group cannot do simple subtraction. While enrolment levels are very high in almost all states, the foundations of basic reading and arithmetic seem weak in the early grades in school.

Another factor highlighted in this report is the difference in the quality of education offered in different parts of India. While $48 \%$ of the children in standard 5 in the state of Gujarat cannot read a story text, only $18 \%$ of the children in the same standard in the state of Kerala cannot read the same story text.

In "SOS for UPE: Self organizing systems for mass education", Mitra (2006) suggested that a school's distance from an urban centre, i.e. its remoteness, affects the quality of education it offers. While the ASER provides us with data to understand the overall regional variations in educational opportunities, it does not consider geographic location as a factor in the quality of education.

The primary objective of the present study is to examine the effects of remoteness on the quality of education in schools. 


\section{Definitions}

For the purposes of this study, we define urban centre, remoteness, and quality of education as follows.

\section{Urban centre}

An urban centre is defined as a location that has:

- A non-agricultural economy

- A higher population density than agricultural areas

- Developed infrastructure

- All basic amenities for a higher standard of living than agricultural areas

- A higher road density than agricultural areas

- Job opportunities in non-agricultural professions

In other words, cities, small and large, would qualify as urban centres.

\section{Remoteness}

Remoteness of a location is measured by its distance from a metropolitan hub, such as Delhi, or any urban centre as defined above. More remote areas tend to have poorer connectivity from the nearest local town, and a lack of roads, public transportation, healthcare, etc. On the basis of remoteness, we studied schools that fall into two categories:

a. Schools that are in the semi-rural category (60-170 $\mathrm{km}$ from Delhi). Such areas tend to have basic facilities, a reasonable standard of living with provisions for entertainment (theatres, restaurants, etc) and generally are well connected to the local urban centre through national or state roads.

b. Schools that are in the rural category (beyond $170 \mathrm{~km}$ from Delhi), are predominantly located on agricultural land. These areas tend to have poorer infrastructure, little or no medical facilities, poorer standards of living, unpaved roads, infrequent local buses or other conveyances to the local urban centre.

While this study is restricted to Northern India, it should be noted that the problem of ensuring quality education outcomes from isolated and remote, rural schools occurs in many parts of the world, including the developed countries, for example, remote parts of Australia, the USA and the UK (for a US example, see Guensberg, 2007).

\section{Quality of education}

A school is considered to offer high quality education if it has good academic performance in examinations. This is the measure used by most governments in assessing school quality. We assume that in order for this to happen, the school needs:

- Motivated and qualified teachers.

- Appropriate infrastructure - adequate school building, electricity, classrooms, basic amenities like drinking water, sanitation, connectivity.

- Appropriate facilities for children - free midday meals, free textbooks, uniforms for children.

Indeed, these assumptions are generally considered to be self evident and are often used for decision making by educational planners and administrators. 
We have used the ASER tests as an indicator of quality and a basis for comparing urban and rural schools, thereby avoiding the need to explain that academic performance in examinations' is not the only way to measure quality.

\section{Research question}

Is quality of education correlated with the distance of a school from the nearest urban center?

Independent variable: Distance from Delhi

Dependent variables: Quality of Education, represented by the overall as well as subject specific performance of the school students' in Hindi, English, Mathematics and Science. To measure this, we used the same tests as were used in the ASER study quoted above (ASER, 2006).

Intervening variables: We assume that the following variables affect the relationship between the independent and dependent variables:

- The average number of students per teacher

- Teachers' qualifications

- Teachers' attitudes towards teaching

- The average number of students per classroom

- Distance from the local urban centers.

\section{Methodology}

Our research was limited to the state of Uttar Pradesh (UP), in northern India. We chose locations between 60 and 260 kilometres from Delhi in a region where local urban centres were few and Delhi was the main urban centre. Table 1 provides a list of the villages and districts that were covered in the present study, and their distance from Delhi. The first eight schools are in semi-rural areas while the others are in rural areas. Examinations of the locations using satellite images from Google maps were used to identify these areas.

Table 1: Schools and their level of remoteness

\begin{tabular}{|c|c|c|c|c|}
\hline Category & $\begin{array}{l}\text { School } \\
\text { No. }\end{array}$ & Village & District & $\begin{array}{l}\text { Distance from } \\
\text { Delhi }(\mathrm{km})\end{array}$ \\
\hline \multirow{8}{*}{$\begin{array}{l}\text { Semi-rural } \\
\text { schools }\end{array}$} & 1 & Bhojpur & Ghaziabad & 60 \\
\hline & 2 & Thori Saat & Ghaziabad & 65 \\
\hline & 3 & Sakauti & Meerut & 120 \\
\hline & 4 & Vailhala & Muzzafarnagar & 150 \\
\hline & 5 & Aazamatgardh & Muzzafarnagar & 170 \\
\hline & 6 & Jamaalpur & Meerut & 130 \\
\hline & 7 & Aichana & Bulandshahar & 120 \\
\hline & 8 & Kasbha Saiana & Bulandshahar & 125 \\
\hline \multirow{8}{*}{$\begin{array}{c}\text { Rural } \\
\text { schools }\end{array}$} & 9 & Rarpati & Etah & 215 \\
\hline & 10 & Neorari & Etah & 220 \\
\hline & 11 & Allipur Madhayan & Badaun & 250 \\
\hline & 12 & Bhavanipur & Badaun & 250 \\
\hline & 13 & Sihori & Etah & 215 \\
\hline & 14 & Garhwala & Etah & 220 \\
\hline & 15 & Rajapur & Mainpuri & 250 \\
\hline & 16 & Nanamauo & Mainpuri & 260 \\
\hline
\end{tabular}



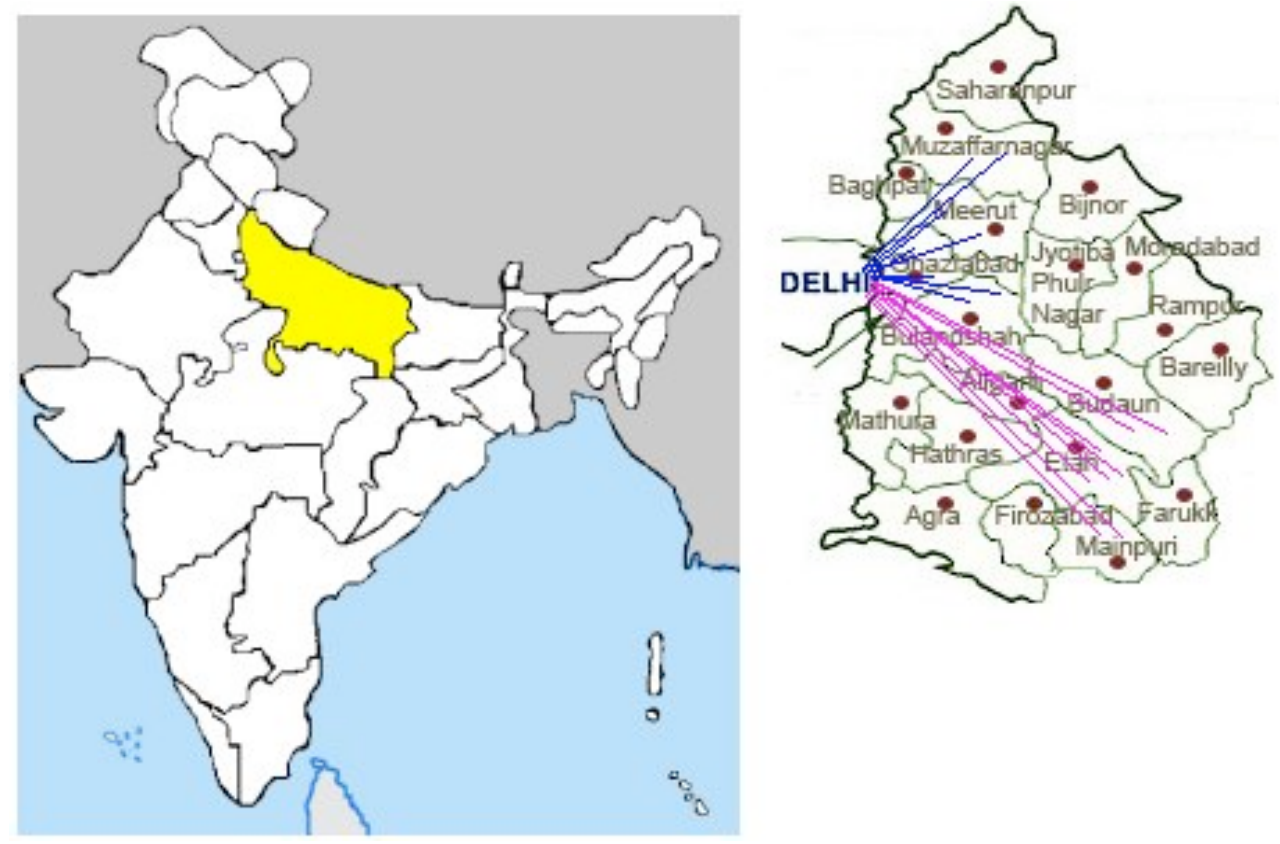

Figure 1: Approximate map of the locations in relation to Delhi

\section{Sample size}

We conducted our study at sixteen Sarva Shiksha Abhiya schools (SSA schools, the "education for all" initiative of the Government of India) by randomly selecting boys and girls between 10 and 12 years of age and from fourth grade to sixth grade. While we aimed to study fifteen children in each of the 16 schools, lower attendance at some of the schools constrained our present sample to a total of 205 children.

\section{Description of the schools studied}

\section{General profile}

All the schools we studied were covered by the Government's Sarva Shiksha Abhiyan (SSA) scheme, which freely provides basic facilities, such as food, water, books and uniforms, to the students (most of whom are members of the "backward classes" and "scheduled castes" of India). However, not all of the sixteen schools studied were executing this scheme fully. Many students did not have uniforms and 2 of the 16 schools we studied had discontinued the midday meal scheme.

\section{Administration}

As the World Bank's sponsorship of a school (a major source of funding in Indian primary education) depends on its enrolments, all applying children are admitted. Children below the sixth grade cannot be failed and are automatically promoted to the next grade regardless of performance. Armed with the certainty that their children will advance to the next class regardless of their attendance at school, parents often keep their children at home or in the fields after they have been admitted into school. 


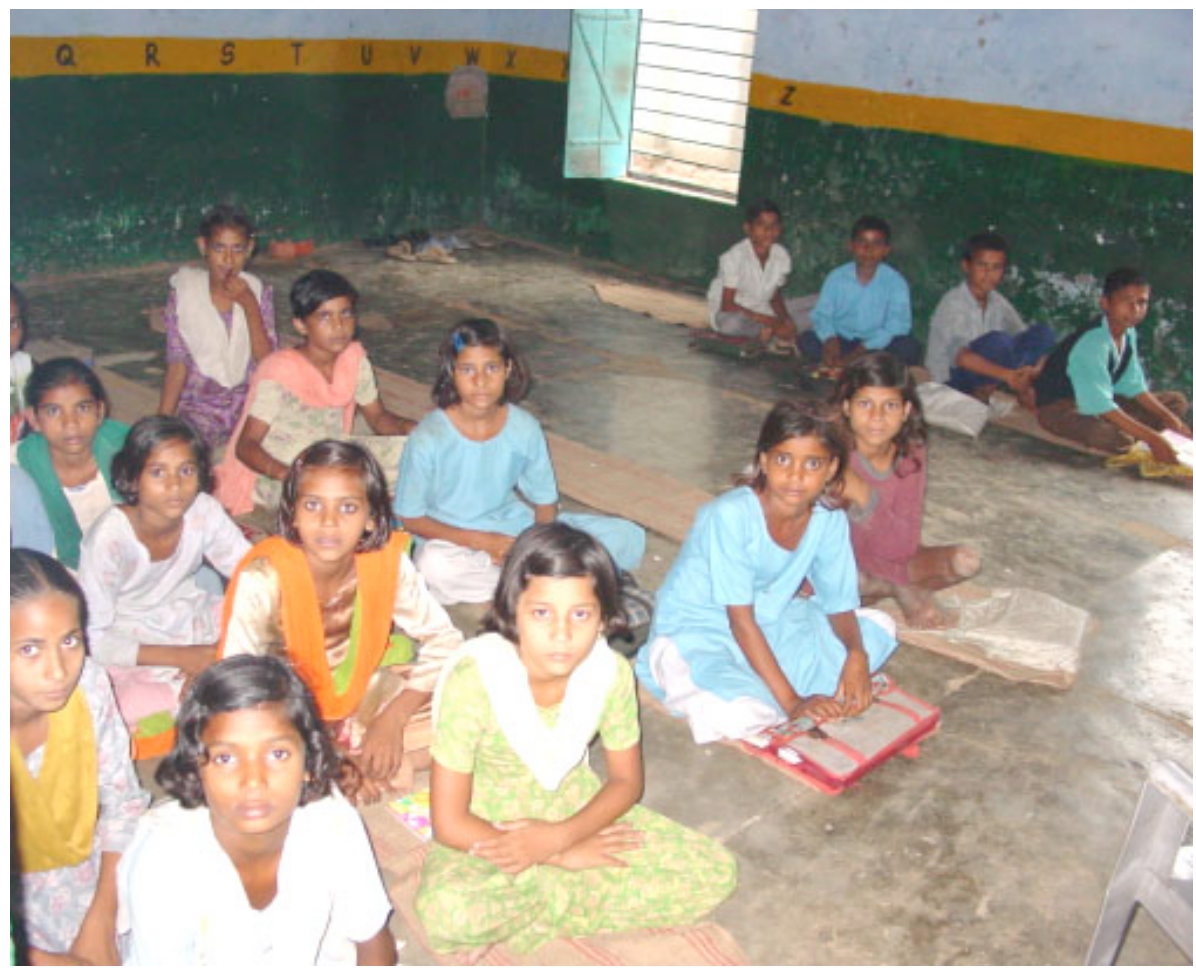

Figure 2: Children sitting in a classroom

An acute shortage of teachers is a common factor at all the studied schools. Unattended classes were reported to be common. Some principals also stated that the teachers were too busy doing governmental clerical work to teach the students. Many schools have resorted to inducting para-teachers, who are not qualified to teach, yet are appointed to oversee the children.

All the teachers at the schools studied have completed the Basic Teacher Certificate Program (BTC), and some have also completed their MCom or MSc degrees privately. Along with their BTCs, all teachers have also attended the government issued Teacher Training Programs at some point of time during their teaching career. However, teachers complain that these training programs have no practical value in the classroom, as they are not taught by experts, but rather by primary school teachers who themselves have received only 2-3 days of training by the DIET (District Institute of Education and Training) staff.

Retiring (50 years and above) and younger generation (30 years and below) teachers at the rural and semi-rural schools have different personal motivations guiding them in their careers. The retiring teachers at both rural and semi-rural schools have grown up children, earn approximately Rs. 12000 (US\$250) per month and are happy living in their present villages, while the younger teachers earn between Rs. 8000 and 14,000 per month. The younger teachers at the semi-rural schools tend to be content, as often they already live in an urban centre, such as a block town or the district headquarters (that is only 2 hours from the village school), or live within a reasonable traveling distance from Delhi. 
On the other hand, younger teachers in the rural schools often desire a change in their current personal situations and prefer to relocate to a larger urban centre, specifically Delhi, Noida and Ghaziabad, which, they feel, would offer them better standards of living and job opportunities than the local town.

\section{School infrastructure}

All the schools we studied are located predominantly in semi-rural and rural areas and are within visible distance of a road. All schools' buildings are made of brick and mortar, though with small and cramped classrooms that lack electricity, proper lighting and ventilation. The schools do not have sufficient urinals, as most are equipped only with two and these are not clean. Along with the infrastructure problems, the schools are inadequately furnished. While all schools have a blackboard as their solitary teaching aid, most of these are worn out and have no dusters or chalk to work with. The schools' only furniture consists of a table and chair for the teachers and principals, while the children sit on mats on the floor. Apart from the muddy fields facing the school compound, the schools have no playgrounds or swing sets for the children's use.

\section{Teaching}

We conducted our studies of the schools approximately one to two hours before they closed for the day. In all the schools that we visited, irrespective of the time and the school, practically all the teachers (including para-teachers) were usually found seated on the chairs mostly in the principal's office; while the students were found to be playing in the schoolyard or were observed seated quietly on the floors (on a mat) in the classrooms or hallways (as shown in Figure 2). We did not observe any teaching methods in practice in the schools during our surveys.

\section{Quality of education}

Quality of education at the schools studied was examined using the following.

\section{Survey of the school}

The remoteness of each school from Delhi was calculated and basic infrastructure such as electricity, number of teachers, school enrollment, number of rooms, types of rooms, teaching aids, playground facilities, etc, were examined. The form designed for this purpose was meant for the collection of purely factual and quantitative data, and did not need pre-testing.

\section{Survey of teachers}

Each of the schools studied had between one and two teachers. All the teachers available in each school were interviewed. A structured questionnaire was used to evaluate their level of academic achievement, reason for working at the school, aspirations, willingness to move to a city, any pedagogical tools that they use and the average number of students per teacher in each school. The factual and quantitative sections of the form did not need pre-testing or validation. However, the qualitative sections of the form were tested for accuracy through a calibration exercise in a school in Delhi.

\section{Performance of the children}

Randomly selected groups of children in each school were administered tests for Hindi, Mathematics, English and Science. For this purpose, we used the same tests as 
used by the ASER quoted earlier (ASER 2006), to enable comparability. The tests had been validated previously (ASER, 2006).

\section{Calculations}

Each school was given a "Total Marks" figure. This was calculated by adding the test scores for each child in each of the subject areas (that is, Hindi, Mathematics, English and Science) to obtain a total for the child and then by taking an average of all the children's total scores for that school. The final figure was converted to a percentage to facilitate comparisons between schools. Each school was also given performance scores in each of the subject areas. These were calculated by averaging the marks obtained by the children of that school in each subject area.

\section{Results}

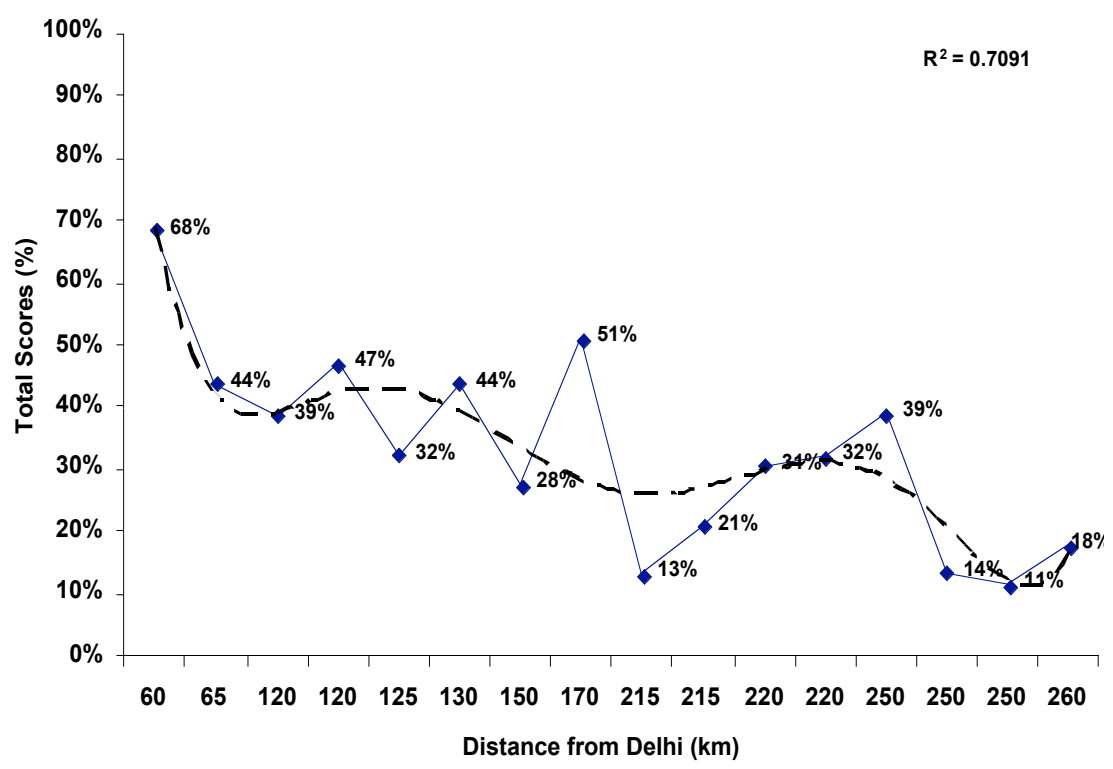

Figure 3: Total marks vs. Distance from Delhi

Figure 3 shows a consistent decline in total marks as one moves away from Delhi. The highest score $(68 \%)$ is observed in the school that is within $60 \mathrm{~km}$ from Delhi and the lowest score (11\%) is observed in the school that is $250 \mathrm{~km}$ from Delhi. Figures 4 to 7 show the marks for all four subjects across the 16 schools plotted against their distances from Delhi.

We find that for all four subjects, Hindi, Mathematics, English and Science, there is a decline as we go further from Delhi.

- Science: Schools beyond a distance of $170 \mathrm{~km}$ showed a larger decrease than for other subjects.

- English: Except for the first school, that is, the one closest to Delhi, performance in English was poor in all other schools with average scores of less than $30 \%$. 
- Hindi and Math: Overall performances decreased with the schools' increasing distance from Delhi. However, the Hindi and Math scores decreased more gradually than scores in Science and English.

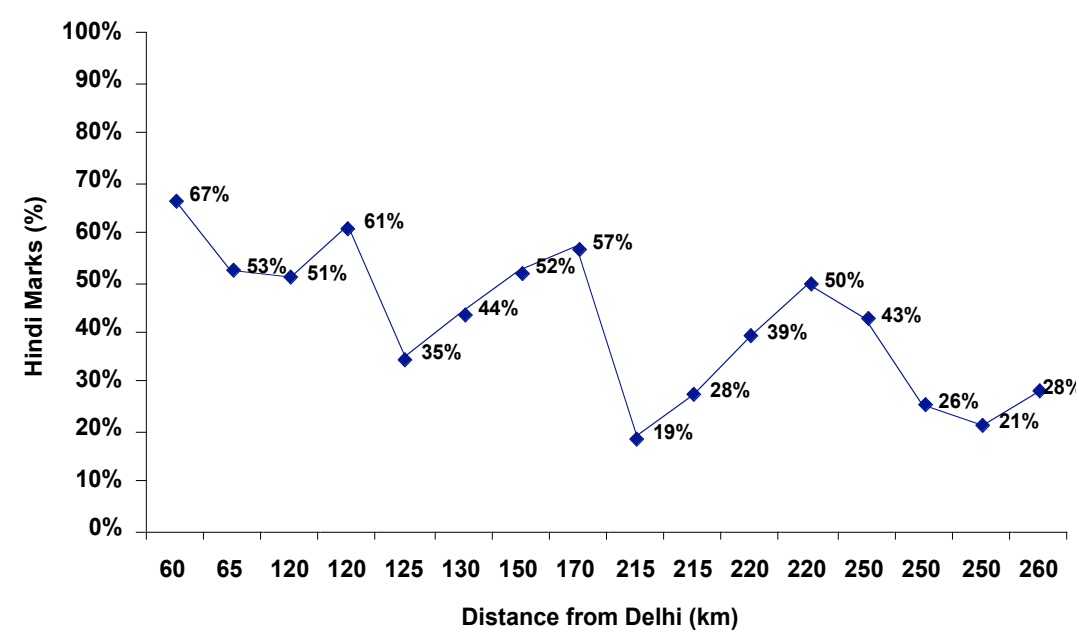

Figure 4: Hindi performance vs. Distance from Delhi

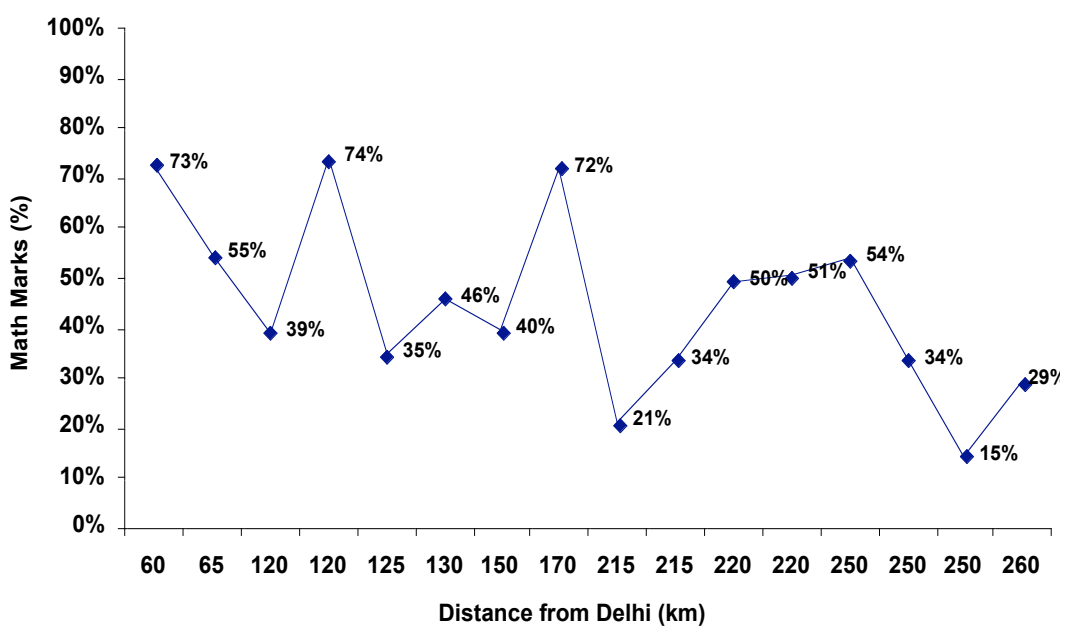

Figure 5: Math performance vs. Distance from Delhi

All the teachers in each of the schools studied were asked if they would like to relocate to an urban centre, if they had the opportunity to. The teachers in 11 out of the 16 schools would like to move to an urban centre, while teachers in 5 schools are not willing to do so. That is, $69 \%$ of the teachers would like to move to Delhi, Ghaziabad and Noida (all large urban centres, often referred to as the National Capital Region) while the remaining 31\% do not want to do so. Moreover, as can be seen from Figure 8, 8 out of the 11 schools where the teachers wanted to migrate to urban centres were located over 200 kilometres away from the nearest urban centre. That is, all teachers in the more remote schools wanted to migrate. 


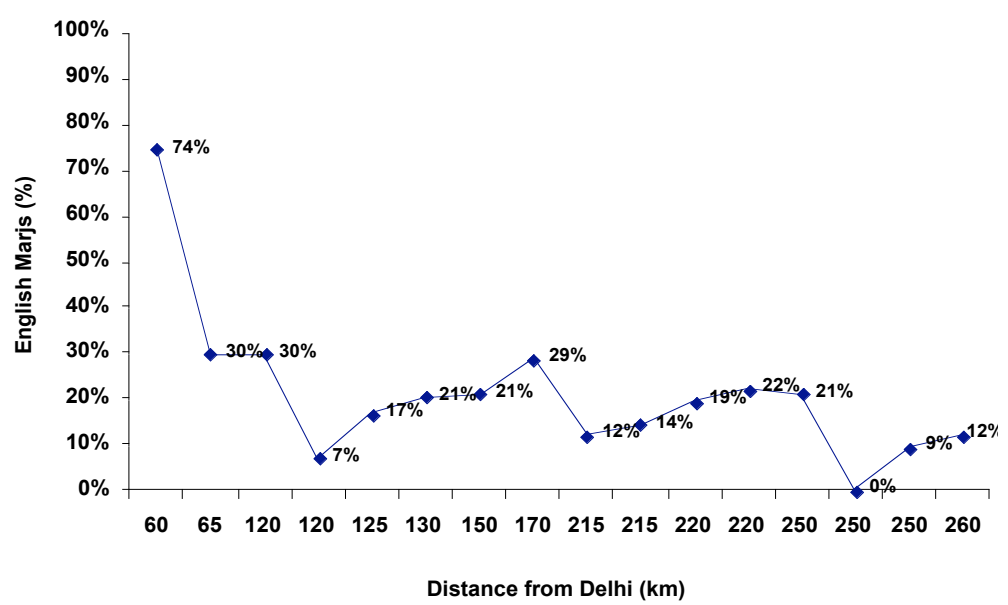

Figure 6: English performance vs. Distance from Delhi

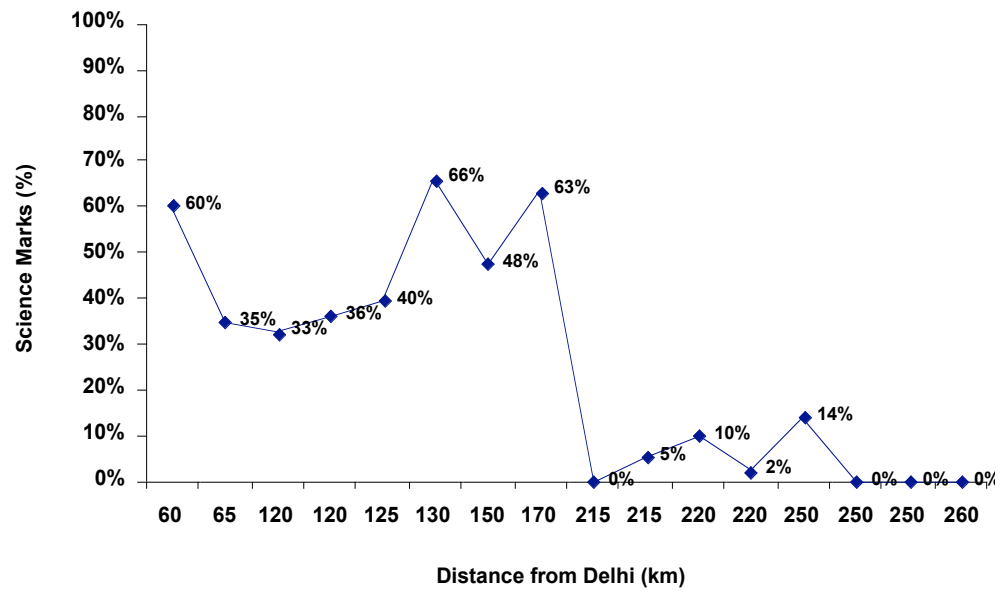

Figure 7: Science performance vs. Distance from Delhi

Would like to Preferences vs. Distance from Delhi

move to an urban centre

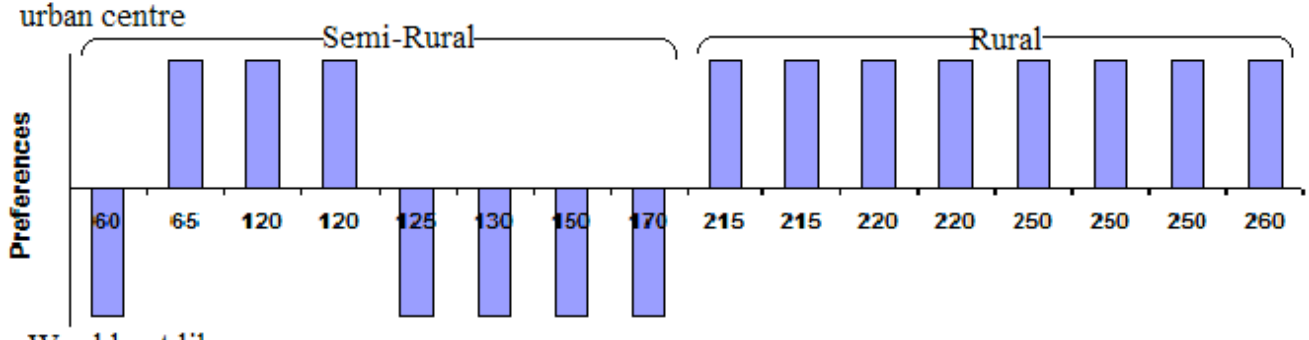

Would not like

to move to an

urban centre

Distance from Delhi $(\mathbf{k m})$

Figure 8: Teachers' preferences with respect to location 
When probed why they would prefer to move to cities, the teachers in the rural areas indicated that they were seeking better job satisfaction, salary structure, standard of living, facilities and educational opportunities.

It is observed that those teachers who expressed their desire to stay in their present locations were all residing in semi-urban areas and had access to basic infrastructure, as well as medical and educational facilities, and reported a relatively good standard of living. Another important observation is that the students in schools where teachers did not wish to migrate to an urban centre had achieved higher scores in all the subject tests.

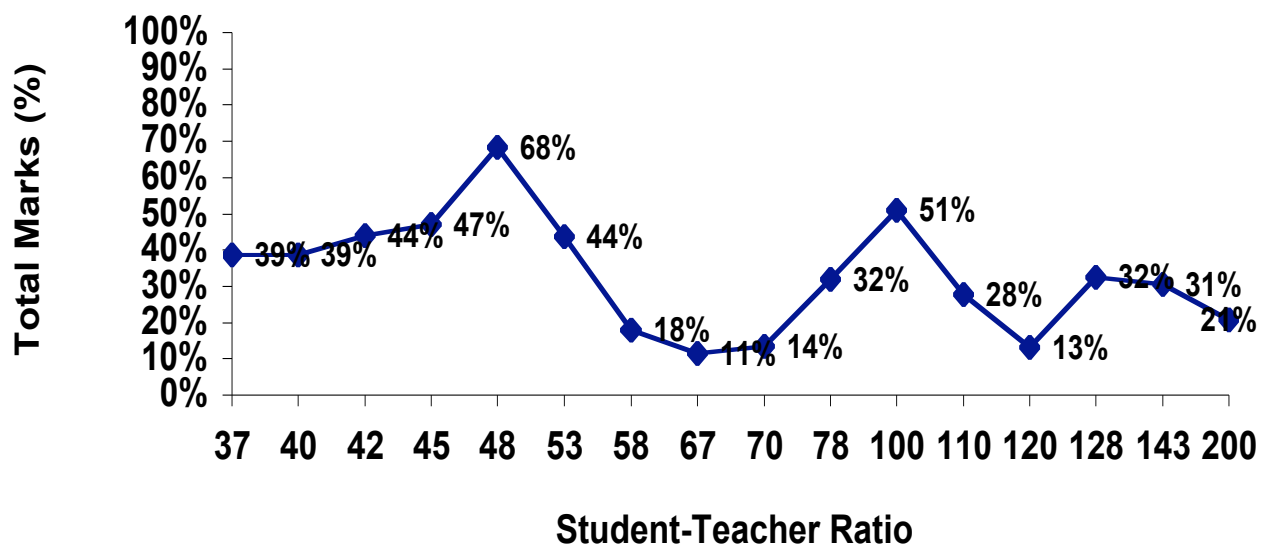

Figure 9: Total marks vs. Average number of students per teacher

Figure 9 indicates no trend and no correlation $(-0.28)$ between marks and the average number of students per teacher for a school. It is interesting to note that the average number of students per teacher varied from 37:1 to 200:1, a very wide variation. However, even so, this seems to have no correlation with student performance.

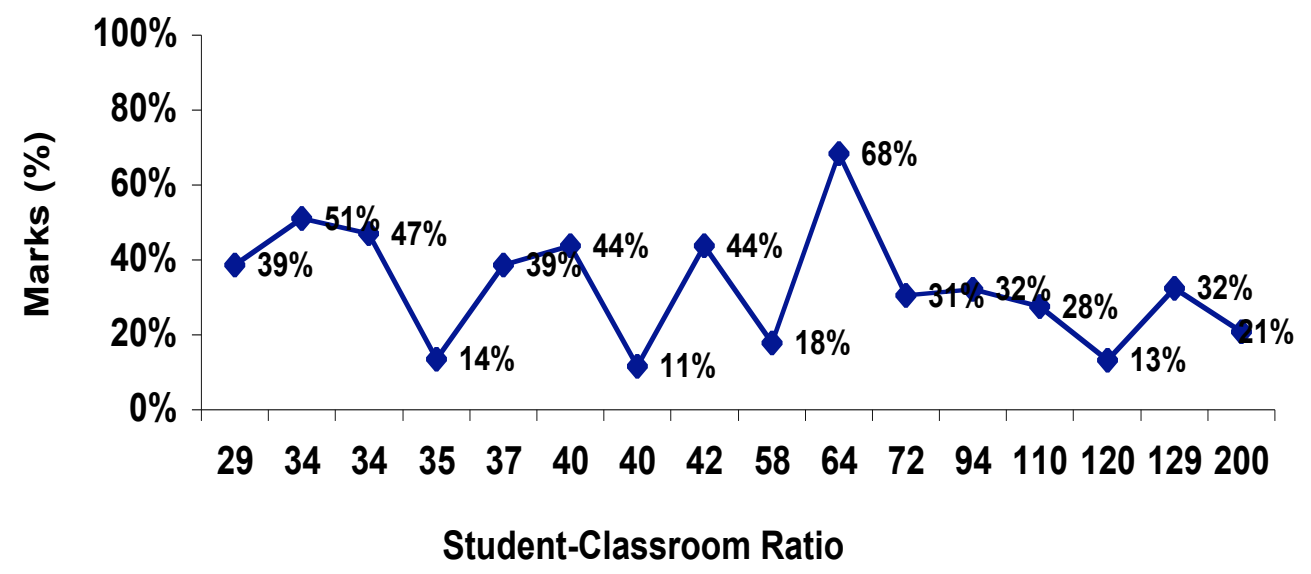

Figure 10: Total marks with respect to student-classroom ratio 
Similarly, Figure 10 indicates no trend and no correlation (0.05) between marks and the average number of students per classroom. The average number of students per classroom varied in the sample from 29 to 200, a very large variation. However, this does not seem to have an impact on the marks obtained by the students. This result seems to support the results obtained in the USA by Hoxby (2000).

\section{Comparison with an urban school}

In order to compare the results obtained in remote schools, an affluent private school in Delhi was studied. The school is popular with high income families in the city. The school's results in the Central Board of Secondary Education examinations are usually excellent and it therefore forms a standard in quality of education. 1500 children attend this school, with an average of 40 students per teacher and 38 students per classroom. The school has many resources. Teachers regularly attend seminars and workshops to improve and advance their pedagogical methods. There is a library, an audiovisual room, science labs and computer rooms. All of the computing resources available at this school are absent from any of the remote schools studied. The school is thus perceived by parents and students as being dedicated to providing the best quality of education for its students.

The same set of tests as had been administered in the remote schools was administered to this school. The results are shown in Table 2. The total score obtained for the school was $93 \%$ while the highest total score obtained in the remote schools was $68 \%$. No teacher in this school wished to move away from an urban centre to a more remote area.

Table 2: Comparative analysis of performance: Urban school and all rural schools

\begin{tabular}{|l|c|c|c|c|c|c|}
\hline \multicolumn{1}{|c|}{ Group } & Hindi & English & Math & Science & Total & SD \\
\hline Control - Delhi & $99 \%$ & $100 \%$ & $92 \%$ & $83 \%$ & $93 \%$ & 3.72 \\
\hline All rural schools & $42 \%$ & $21 \%$ & $45 \%$ & $26 \%$ & $33 \%$ & 15.71 \\
\hline
\end{tabular}

\section{Conclusions}

This study is over a small sample and in a specific geographic area in India. It is necessary to be very cautious in generalising about the findings from this work. However, we think that the results point towards some interesting possibilities. It is in this spirit that the following conclusions should be considered.

The quality of education provided by a school is:

1. Inversely related to the remoteness of the school from its nearest urban centre.

2. Not related to the average number of students per teacher in the school.

3. Not related to the average number of students per classroom in the school.

If a teacher wishes to migrate to another location, the performance of his or her students seem to decline. The nature and motivation of a teacher seems to affect the quality of education, almost independently of other factors such as overcrowding (too many students to a teacher or classroom), or school facilities, which were almost identical in all the schools studied. In remote areas, as we see in Figure 8, most of the teachers $(69 \%)$ want to migrate to their nearest urban centres (Delhi, Ghaziabad or Noida, in this sample). 
On the basis of the above, one could argue that the motivation of teachers to continue in a school affects the achievement of their students.

In this connection, it is important to point out that the terms "remote" and "migrate" do not, necessarily have to be in the context of physical, geographical distance. Schools in many areas of large cities, both in the developed and developing countries show a decline in the quality of education in slums, ghettoes and other disadvantaged areas of the city (see for instance, Harrison, 1972). It is reasonable to suppose that these schools, like those in our rural sample above, also have a teacher migration and motivation problem. We suggest that some areas of urban cities are socially, culturally and/or economically "remote" from other areas of the city. While this study is about geographical remoteness, it is interesting to propose that these other kinds of remoteness as described above could also lead to teacher migration with an attendant decline in the quality of education.

The Indian Government as well as governments of many other countries spend large amounts of their education funds for the training of teachers, in the hope that this will improve the quality of education. This expectation may have an intrinsic flaw when applied to remote areas. Wherever a teacher wants to migrate away from the school he or she is employed in, teacher training will only enable them to do so more easily. There will always be areas on the planet where good teachers will not want to go (see, for instance, Hindustan Times, 2007; Thomas, 2003).

We suggest that alternative methods that do not rely on teacher quality and motivation should be introduced into remote schools. The results from this study could be used to support the point of view that educational technologies, particularly those that enable learners to achieve educational objectives without teachers (Inamdar, 2004, Mitra et al 2005, 2006), should be introduced into remote schools. Indeed, such technologies should be introduced into schools where, for whatever reason, teachers are either absent or unwilling to go.

Usually, new educational technology is piloted in affluent, urban schools. Such schools already have good students and teachers. By piloting new technology in such environments we may conclude that technology is not useful to school education (see, for instance $B B C$ News, 2004). It is in remote areas, at the "bottom of the pyramid", that alternative learning methods may do most to improve the quality of education in schools that are remote from urban centres (Inamdar, 2004; Mitra, 2006).

There are a few shortcomings in the development, testing and eventual deployment of educational technology. Most of the technologies used in schools and other educational institutions are borrowed from other application areas. For example, Microsoft PowerPoint is one of the most commonly used applications in educational institutions. However, it was not designed for the use of educators and learners - it was designed for business communications. The personal computer itself is designed for climate controlled and electrically stable environments such as found in most offices and businesses. They are not designed for use in rugged or outdoor environments and also not designed for use by children. Projectors, screens, "smart" boards, video conferencing, etc, are all technologies that have been designed and invented for use by businesses. It is necessary to design and develop technology that can, to whatever extent possible, provide education, without teachers, in those areas where good teachers are not willing to go. Educational technology should be designed for, and go first, into the remotest areas. 


\section{Acknowledgements}

Financial support from The NIIT Institute and resources provided from the School of Education, Communication and Language Sciences of Newcastle University are gratefully acknowledged.

\section{References}

ASER (Annual Status of Education Report) (2006). Annual Status of Education Report, January 17, 2005. http: / / pratham.org/aserrep.php [viewed 5 Feb 2007]

Hindustan Times (2007). Editorial: A classroom struggle. 13 August. [viewed 15 Jan 2008]. http: / / www.hindustantimes.com/StoryPage/StoryPage.aspx?id=71f07c80-ba5a-4724-a08de76d18bd3f24

Hoxby, C. (2000). The effects of class size on student achievement: New evidence from population variation. The Quarterly Journal of Economics, 115(4), 1239-1285. [viewed 5 Feb 2007, not found 3 Feb 2008] http:/ / www.economics.harvard.edu/faculty/hoxby/papers/ effects.pdf

Guensberg, C. (2007), Claudette Morton: Enriching resources at isolated rural schools. Edutopia, June. http:/ / www.edutopia.org/claudette-morton/

Harrison, B. (1972). Education and underemployment in the urban ghetto. American Economic Review, 62(5), 796-812.

Inamdar, P. (2004). Computer skills development by children using 'hole in the wall' facilities in rural India. Australasian Journal of Educational Technology, 20(3), 337-350.

http: / / www.ascilite.org.au/ajet/ajet20/inamdar.html

Mitra S. (2006). SOS for UPE: Self organizing systems for mass education. eGov monitor, 4 May. [viewed 5 Feb 2007; verified 3 Feb 2008] http:/ / www.egovmonitor.com/node/5865

Mitra, S., Dangwal, R., Chatterjee, S., Jha, S., Bisht, R. S. \& Kapur, P. (2005). Acquisition of computing literacy on shared public computers: Children and the "hole in the wall". Australasian Journal of Educational Technology, 21(3), 407-426. http:/ / www.ascilite.org.au/ajet/ajet21/ mitra.html

BBC News (2004). Doubts about school computer use. 24 November. [viewed 5 Feb 2007, verified 3 Feb 2008]. http: / / news.bbc.co.uk/1/hi/education/4032737.stm

Thomas, B. S. (2003). Disturbing teacher migration tremors. India Together, December. [viewed 15 Jan 2008, verified 3 Feb 2008]. http: / / www.indiatogether.org/2003/dec/edu-migrate.htm

Sugata Mitra, Professor of Educational Technology, School of Education,

Communication and Language Sciences, Newcastle University, Newcastle upon Tyne.

NE1 7RU, United Kingdom. Email: sugata.mitra@ncl.ac.uk

Ritu Dangwal and Leher Thadani, Centre for Research in Cognitive Systems, The NIIT Institute of Information Technology, Balaji Estate, Kalkaji Extension, New Delhi 110091, India. Email: ritud@tni.edu.in 